\title{
Predictive Factors Of Liver Metastasis After Curative Treatment For Colorectal Cancer
}

\section{Kolorektal Kanserli Hastalarda Küratif Tedavi Sonrası Karaciğer Metastazını Predikte Eden Faktörler}

\author{
Cemil Hocazade ${ }^{1}$, Nuriye Yıldırım ${ }^{1}$, Yakup Bozkaya ${ }^{1}$, Gökhan Uçar ${ }^{1}$, Nurullah Zengin ${ }^{1}$ \\ ${ }^{1}$ Ankara Numune Eğitim ve Araştırma Hastanesi, Tıbbi Onkoloji Kliniği
}

Dergiye Ulaşma Tarihi:13/11/2015 Dergiye Kabul Tarihi:23/12/2015 Doi: 10.5505/aot.2016.25993

\section{ÖZET}

Giriş ve Amaç: Kolorektal kanserler dünya genelinde en s1k görülen kanserlerden biridir. Karaciğer metastazı tanıdan kısa bir süre sonra gelişebilir. Daha önce tedavi almış kolorektal kanserli hastalarda karaciğer metastazektomi yapılması 5 yıllık sağkalımı \%20-40 oranında arttırabilir. Bu çalışmada erken evre kolorektal karsinomlu hastaların karaciğer nüksünü erken dönemde predikte edebilecek faktörleri araştırmayı amaçladık.

Yöntem ve Gereçler: Çalışmamıza Ankara Numune Eğitim ve Araştırma Hastanesi Tıbbi Onkoloji Kliniğginde 2009 Ocak- 2014 Ağustos aylarında takibe alınarak tedavi planı yapılan non-metastatik 517 hasta dahil edilmek üzere değerlendirildi. Birinci grupta karaciğer dışı nüksü olan hastalarla beraber nüks olmadan takibe devam edilen hastalar varken 2.grupta ise karaciğer metastazı gelişen hastalar mevcuttu. Hastaların tanı anındaki laboratuar sonuçları receiver operating characteristic (ROC) curve analizi uygulanarak laktat dehidrogenaz (LDH), karsinoembriyonik antijen (CEA) ve gama glutamil transferaz (GGT) için cut off değerleri belirlendi (s1rasiyla, $400 \mathrm{U} / \mathrm{L}, 50 \mathrm{ng} / \mathrm{ml}$ ve $90 \mathrm{U} / \mathrm{L}$ ).

Bulgular: Univariate analizde CEA değeri yüksek olan 20 hastanın 7'sinde (\%35), düşük olan 206 hastanın 28 'inde $(\% 8,7) \mathrm{kc}$ metastazı gelişmişti $(\mathrm{p}<0,001)$. LDH değerine göre karaciğer nüksüne bakıldığında ise yüksek olan 15 hastanın 5'inde $(\% 33,3)$, düşük olan hasta grubunda 189 hastadan 17 'sinde (\%9) takipte karaciğer metastazı gelişti ( $\mathrm{p}=0,003)$. GGT değerine göre ise yüksek olan 15 hastanın 5 'inde $(\% 33,3)$, düşük olan 244 hastanın 24'ünde $(\% 9,8)$ karaciğer nüksü gelişmişti $(\mathrm{p}=0,005)$. Multiple lojistik regresyon analizi ile değerlendirildiğinde LDH anlamlılığını korumaktaydı ( $p=0,047$, OR 7,8: 1,02-59,3).

Tartışma ve Sonuç: Karaciğer metastazı kolorektal kanser tanısı alan hastalarda surveyi etkileyen önemli bir faktördür. Bizim çalışmamızda LDH yükseliğinin karaciğer nüksünü predikte etmede kullanılabilecek uygun bir fakör olduğu görüldü fakat bu sonucun prospektif randomize çalışmalarla desteklenmesi gerekmektedir.

Anahtar Kelimeler: Kolorektal kanser, karaciğer, nüks

\section{ABSTRACT}

Introduction: Colorectal cancer (CRC) is one of the most commonly detected cancers worldwide. Liver metastasis might develop shortly after the diagnosis of colorectal cancer. Liver metastasectomy might improve the five year survival rate to $20-40 \%$ in patient with previously treated CRC. We aimed in this study to evaluate the predictive factors to liver metastases in patients with newly diagnosed non metastatic CRC.

Methods: Five hundred and seventeen non-metastatic colorectal patients followed at Medical Oncology Department of Ankara Numune Training and Research Hospital between January 2009 and August 2014 were evaluated retrospectively. Patients were divided in to the two subgroups. Group 1 consisted of non-metastatic and metastatic patients except liver metastases. Group 2 consisted of patients with liver metastases. Laboratuary results at the time of diagnosis were evaluated with receiver operating characteristic (ROC) Curve analysis and cut-off values were determined for lactate dehydrogenase (LDH), carcinoembryonic antigen (CEA) and gama glutamil transferase (GGT) with (400 U/L, $50 \mathrm{ng} / \mathrm{ml}$ and $90 \mathrm{U} / \mathrm{L}$, respectively).

Results: There were 7 cases (\%35) with high CEA levels in Group 2 and $28(\% 8,7)$ cases in Group 1 . There was a significant difference between this subgroups in univariate analysis $(p<0,001)$. According to LDH levels, there were $5(\% 33,3)$ liver metastases in high LDH group and $17(\% 9)$ liver metastases in low LDH group (p=0,003). There were 5 cases $(\% 33,3)$ of liver metastases in patients with high GGT and 24 cases $(\% 9,8)$ in patients with low GGT $(\mathrm{p}=0,005)$. LDH was remained only significant factor after multiple logistic regression analysis (OR 7,8: 1,02-59,3).

Discussion and Conclusıon: Hepatic metastases from colorectal cancer were an important predictive factor of overall survival. In our study we showed that high LDH levels at the time of diagnosis might be useful predictive factor of liver metastases. We need prospective randomized studies to determine effect of high LDH levels in colorectal cancer.

Keywords: Colorectal cancer, liver, recurrence 


\section{Giriş}

Kolon kanseri dünya genelinde en s1k görülen kanserlerden olup erkeklerde akciğer ve prostat kanserinden sonra üçüncü sırada kadınlarda ise meme kanserinden sonra ikinci siradadir $(1,2)$. Karaciğer metastazı hastaların yaklaşık 1/3'ünde gelişmekte olup kolon kanserli hastalarda önemli bir ölüm sebebidir $(3,4)$. Sınırlı karaciğer metastazı olan hastalarda metastazektomi yapılması sonrasi 5 y1llık sağkalım oranı \%20 ile \% 40 arasındadır (5). Fakat metastazektomi sonras1 hastaların 2/3'ünde nüks gelişmektedir (6-8). Tanı anında bazı tümör özellikleri karaciğer metastazı varlığı ile korelasyon gösterir, bunlar sirasıyla lenf nodu metastazi, tömör $\mathrm{t}$ evresi, venöz invazyon, tümör grade ve inflamatuar hücre reaksiyonlarıdır. Laminin, CD44, Matrix metalloproteinaz ve sialy-lewis $\mathrm{x}$ gibi bazı moleküler özelliklerde karaciğer metastazı ile birliktelik gösterir (9).

$\mathrm{Bu}$ çalışmada tanı anında uzak metastazı olmayan erken evre kolorektal karsinomlu hastaların karaciğer nüksünü predikte edebilecek faktörleri araştırmayı amaçladık.

\section{Gereç ve Yöntem}

Çalışmamıza Ankara Numune Eğitim ve Araştırma Hastanesi Tıbbi Onkoloji Kliniğinde 2009 Ocak- 2014 Ağustos aylarında takibe alınarak tedavi planı yapılan non-metastatik 517 hasta dahil edildi. Hastaların hepsine 2 onkolojik cerrahi grubu tarafindan küratif amaçlı cerrahi uygulanmıştı. Takipte hastalar 2 gruba ayrıldı 1.grupta karaciğer dışı nüksü olan hastalarla beraber nüks olmadan takibe devam edilen hastalar varken 2.grupta ise karaciğer metastazı gelişen hastalar mevcuttu. Hastaların tanı anındaki laboratuar verileri incelenerek karsinoembriyonik antijen (CEA) değeri 50 $\mathrm{ng} / \mathrm{ml}$ alt1 ve üzeri, laktat dehidrogenaz (LDH) değeri $400 \mathrm{U} / \mathrm{L}$ altı ve üzeri ve gama glutamil transferaz (GGT) $90 \mathrm{U} / \mathrm{L}$ altı ve üzeri olarak gruplandırıldı. Hastalar hem univariate hem de multivariate analiz yapılarak karaciğer nüksü predikte eden faktörler araştırıldı.

Tüm istatistiksel analiz spss 18.0 kulllanılarak yapıldı. Hastaların demografik özellikleri frekans yöntemi kullanılarak belirlendi. Cut off değerler receiver operating characteristic (ROC) analizi yapilarak belirlendi. Gruplar arasındaki istatistiksel farklar ki-kare testi kullanılarak hesapland1. Univariate analizde anlamlı çıkan sonuçlar multiple logistic regression analizi ile tekrar değerlendirildi.

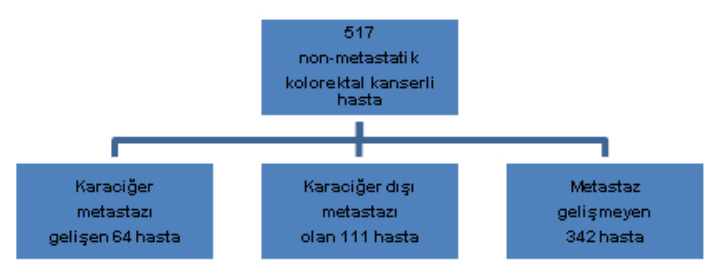

\section{Bulgular}

Çalışmamıza dahil edilen hastaların 309'u erkek (\%59,8), geri kalanı kadın hastaydı $(\% 40,2)$. Hastaların medyan yaşları 58 (range 22-95) olup, tanı anında hastaların hiçbirinde metastaz bulgusu yoktu. Tanı evreleri sirasiyla evre 1 hasta say1s1 67 $(\% 12,9)$, evre 2 hasta sayıs1 $248(\% 47,9)$ ve evre 3 ise 202 hasta $(\% 39,2)$ şeklindeydi. Lenf nodu pozitif hastaların 78 'i N1 $(\% 37,5)$ geri kalan hastalar N2 $(\% 62,5)$ idi. Hastaların takibinde 175 hastada (\%33.8) nüks gelişirken, 64 hastada karaciğer nüksü vard1 $(\% 12,4)$ (Tablo 1).

Tablo 1. Kolorektal kanserli hastaların demografik özellikleri

\begin{tabular}{|c|c|c|c|}
\hline \multicolumn{1}{|c|}{ Yaş } & Medyan & 58 & \multicolumn{1}{|c|}{} \\
\hline \multirow{2}{*}{ Cinsiyet } & Erkek & 309 & $\% 59,8$ \\
\cline { 3 - 4 } & Kadın & 208 & $\% 40,2$ \\
\hline \multirow{2}{*}{ Evre } & 1 & 67 & $\% 12,9$ \\
\cline { 3 - 4 } & 2 & 248 & $\% 47,9$ \\
\cline { 3 - 4 } & 3 & 202 & $\% 39,2$ \\
\hline \multirow{2}{*}{ Nüks } & Karaciğer & 64 & $\% 12,4$ \\
\cline { 3 - 4 } & Toplam & 175 & $\% 33,8$ \\
\hline & & & \\
\hline
\end{tabular}

Univariate analizde CEA değeri yüksek olan 20 hastanın 7'sinde karaciğer

Adress for correspondence: Uzm. Dr. Cemil Hocazade. Ankara Numune Eğitim Ve Araştırma Hastanesi Sıhhiye Ankara - Türkiye 
nüksü gelişirken (\%35), düşük olan 206 hastanın 28'inde $(\% 8,7)$ karaciğer metastazı gelişmişti $(p<0,001)$. LDH değerine göre karaciğer nüksüne bakıldığında ise yüksek olan 15 hastanın 5'inde $(\% 33,3)$ karaciğer metastazı gelişmiş iken düşük olan hasta grubunda 189 hastadan 17'sinde (\%9) takipte karaciğer metastazı gelişti $(p=0,003)$. GGT değerine göre ise yüksek olan 15 hastanın 5 'inde $(\% 33,3)$ karaciğer nüksü varken düşük olan 244 hastanın 24 'ünde $(\% 9,8)$ karaciğer nüksü gelişmişti $(\mathrm{p}=0,005)$ (Tablo 2$)$.

Tablo 2. CEA, LDH ve GGT'ye göre nüks oranları

Hastalar tümör invazyon derinliğine

\begin{tabular}{|c|c|c|c|c|c|}
\hline & \multicolumn{4}{|c|}{ Karaciğer metastazı } & \multirow[b]{2}{*}{$\mathrm{p}$} \\
\hline & pozitif & $\%$ & negatif & $\%$ & \\
\hline $\mathrm{CEA} \geq 50$ & 7 & 35,0 & 13 & 65,0 & \\
\hline CEA $<50$ & 28 & 8,7 & 178 & 91,3 & $<0,001$ \\
\hline $\mathrm{LDH} \geq 400$ & 5 & 33,3 & 10 & 66,7 & \\
\hline $\mathrm{LDH}<400$ & 17 & 9,0 & 172 & 91 & 0,003 \\
\hline $\mathrm{GGT} \geq 90$ & 5 & 33,3 & 10 & 66,7 & \\
\hline GGT $<90$ & 24 & 9,8 & 220 & 90,2 & 0,005 \\
\hline
\end{tabular}

göre değerlendirildiğinde sırasıyla evre1-4 için karaciğer nüksü şu şekildeydi, $0 \quad(\% 0), 3$ $(\% 5,2), 33(\% 10,4)$ ve T4 tümörlerde 28 $(\% 20,2)$ şeklindeydi $(p=0,004)$. Lenf nodu durumuna göre hastalar değerlendirildiğinde ise lenf nodu negatif hastaların 28 'inde $(\% 8,8)$, N1 hastaların 22' sinde $(\% 16,5)$ ve N2 hastaların 14 'ünde $(\% 16,4)$ karaciğer nüksü mevcuttu $(p=0,031)$. Lenfovasküler invazyonu (LVI) olan hastalarm 20'sinde (\%17,9) karaciğer metastazı gelişirken invazyon olmayanların 27 'sinde $\quad(\% 9,9) \quad$ karaciğer

\section{Tartışma}

Kolorektal kanser dünya genelinde kansere bağl1 ölümlerin önemli sebeplerinden biridir. Karaciğer metastazı küratif tedavi sonrası prognozu etkileyen önemli bir faktördür. metastazı vardı $(\mathrm{p}=0,03)$. Perinöral invazyon (PNI) değerlendirildiğinde bu oranlar \%19,6'ya \%9,8 şeklindeydi $(\mathrm{p}=0,01)$ (tablo 2$)$. Multiple lojistik regresyon analizi ile değerlendirildiğinde $\mathrm{LDH}$ anlamlılığını korumaktayd $1(\mathrm{p}=0,047$, OR 7,8: 1,02-59,3) (Tablo 3).

Tablo3. Tümör özelliklerine göre karaciğer metastazı

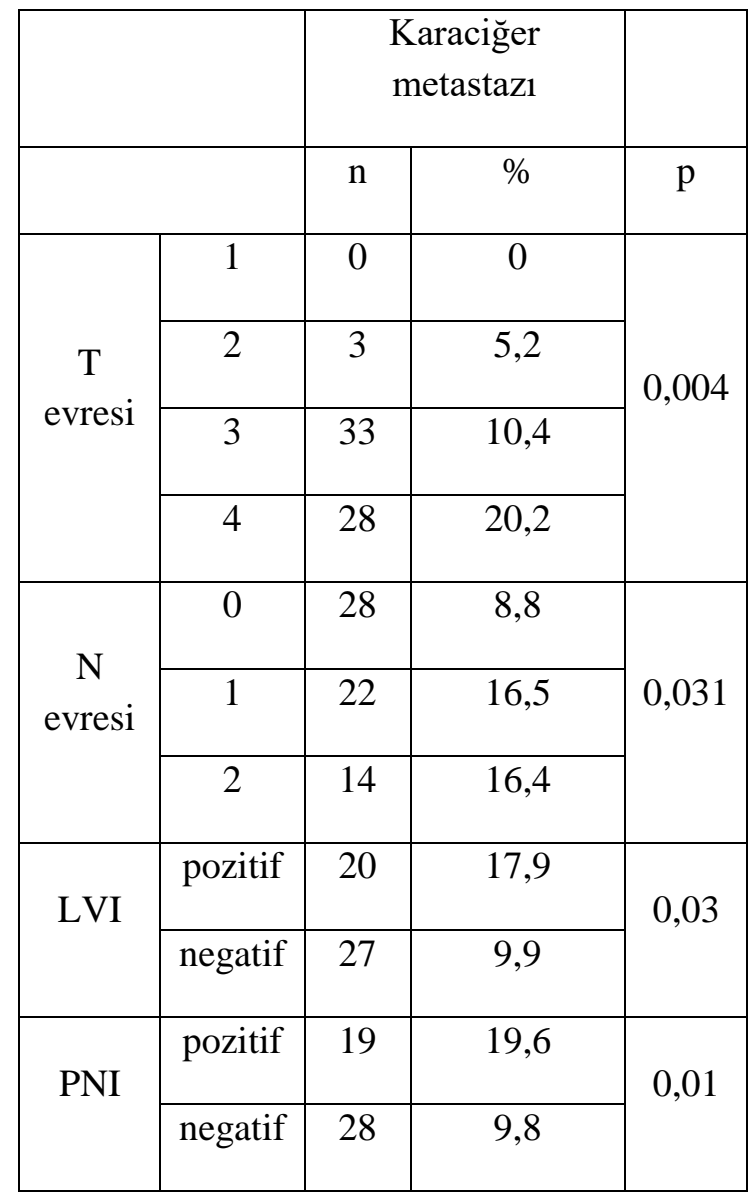

Hastalar karaciğer metastazı gelişim zamanlarına göre değerlendirildiğinde, GGT yüksek olan hastaların median nüks zamanı 7,6 ay iken GGT normal olan hastaların nüks zamanı 13,8 ayd $1(p=0,21)$. LDH değerine göre değerlendirildiğinde ise yüksek olan grupta 7,6 ay iken diğer grupta 16,7 ay idi $(p=0,68)$.

Birçok çalışma karaciğer metastazlarının cerrahi olarak çıkarılmasının sağkalımı arttırdığını göstermiştir (10). Karaciğer metastazı olabildiğince erken evrede tanı alırsa cerrahi uygulanma şansı o derece artar. Tanı anında görüntüleme tetkiklerinde 
olmayan karaciğer metastazlarını predikte edecek faktörler klinik seyir için ayrı bir önem arz eder.

Karaciğer metastazının tanı anında tümör invazyon derinliği, venöz invazyon ve lenf nodu metastazı varlığı ile yakın ilişkili olduğu gösterilmesine rağmen bu faktörlerin zayıf prediktif etkisi sebebi ile kullanımı kisitlidir (11-13). Bu sebeple tanı anında karaciğer metastazını predikte edecek farklı faktörler araştırılmıştır. Sun ve arkadaşlarının yaptığı çalışmada haptoglobulin ve osteopontinin tumor dokusunda 1mmunhistokimyasal olarak değerlendirilmiş, haptoglobulin pozitifliği olan hasta grubunda takipte karaciğer nüks riski (odds ratio) 85.5 kat daha yüksekken $(\mathrm{p}<0,001)$ osteopontin pozitifliğinde risk 55,4 kat artmakta olduğu gösterilmiş $(p=0,001)(14)$. Yine bir başka çalışmada prostaglandin I2 sentaz (PTGIS) ekspresyonu heterokron karaciğer metastazı olan hastaların \%87'sinde pozitifken, nonmetastatik hasta grubunda ise $\% 49$ pozitiflik göstermekteydi. Multi regresyon analizi yapıldığında PTGIS pozitifliğinin heterokron karaciğer metastaz gelişim riskinin 3,5 kat artışı ile birlikte olduğu gösterilmiş $(\mathrm{p}<0,001)$ (15). $\mathrm{P}$ antijen ailesi üye 4 (PAGE4) pozitifliğinin değerlendirildiği bir başka çalışmada ise PAGE4 overekspresyonun karaciğer metastazını predikte etmede 2,5 OR ile kullanılabilir bir prediktif marker olduğu düşünülmüştür $(p=0,04) \quad(16)$. Fang ve arkadaşlarının yaptığı bir başka çalışmada ise tumor dokusunda matrix metalloproteinaz-7 (MMP7) over ekspresyonunun karaciğer metastazını predikte etmede etkili olabileceği gösterilmiştir (OR 6,7, p=0,003) (17). Bu çalışmaların tamamında olası biyolojik markerların tamamı tümör dokusunda bakılmış olup kullanımları kısıtlı kalmıştır, bu sebeple tanı anında karaciğer metastazını predikte edebilecek kolay ulaşılabilir ve daha ucuz belirteçler gerekmektedir. Çalışmamızda GGT yüksekliği olan hastaların takipte $\% 33,3$ 'ünde karaciğer metastazı geliştiğini gösterdik $(\mathrm{p}=0,005)$, ayrıca istatistiksel olarak anlamlı olmasa da GGT yüksek olan hastalarda normal olan hastalara göre daha erken dönemde karaciğer metastazı geliştiğini gördük. Benzer şekilde LDH değeri yüksek olan hastalardan \%33,3'ünde karaciğer metastazı gelişmişti bu oran normal olan grupta $\% 9,0$ idi $(\mathrm{p}=0,003)$. Tanı anında yüksek LDH değeri olan gruptaki hastaların medyan karaciğer metastazı geliştirme zamanları 7,6 ay iken diğer grupta 16,7 ay idi $(p=0,68)$, bu sonuç istatistiksel olarak anlamlı olmasa da klinik olarak anlamlı olduğu düşünüldü. Multiple lojistik regresyon analizi ile değerlendirildiğinde LDH dışındaki tüm faktörlerin anlamlılığını yitirdiği görüldü. LDH yüksekliği olan hastalarda karaciğer metastazı gelişme riski LDH normal olan gruba göre 7,8 kat daha fazla idi $(p=0,047)$.

Sonuç olarak karaciğer metastazı kolorektal kanser tanısı alıp küratif rezeksiyon yapılan hastalarda surveyi etkileyen önemli bir faktör olması sebebi ile nüks öncesi bu durumu predikte edecek faktörlerin bulunmasının önemi büyüktür. Bizim çalışmamızda LDH yüksekliğinin karaciğer nüksünü predikte etmede kullanılabilecek uygun bir faktör olduğu görüldü fakat bu sonucun başka çalışmalarla desteklenmesi ve standardize edilmesi gerekmektedir.

Çıkar Çatışması: Yok

\section{Kaynaklar}

1. Siegel R, Ma J, Zou Z, Jemal A. Cancer statistics, 2014. CA Cancer J Clin. 2014;64:9-29.

2. Kim JH. Chemotherapy for colorectal cancer in the elderly. World J Gastroenterol. 2015;21(17):51585166.

3. Chang A, Schneider P, Sugarbaker P, Simpson C, Culnuane M, Steinberg S. A prospective randomized trial of regional versus systemic continuous 5fluorodeoxyuridine chemotherapy in the treatment of colorectal liver metastasis. Ann Surg 1987;206:685-93.

4. Sugihara K. Continuous hepatic arterial infusion of 5-fluorouracil for unresectable colorectal liver metastases: phase II study. Suirely 1995; 117:624-8.

5. Choi HJ, Hyun MS, Jung GJ, Kim SS, Hong SH. Tumor angiogenesis as a prognostic predictor in colorectal carcinoma with special reference to mode of metastasis and recurrence. Oncology 1998;55: 575-581

6. Fong Y, Cohen AM, Fortner JG, Enker WE, Turnbull AD, Coit DG, et al.. Liver resection for colorectal metastases. J Clin Oncol 1997; 15: 938-946

7. Bozzetti F, Doci R, Bignami P, Morabito A, Gennari L. Patterns of failure following surgical resection of colorectal cancer liver metastases. Rationale for a multimodal approach. Ann Surg 1987;205: 264-270

8. Ueno H, Mochizuki H, Hashiguchi Y, Hatsuse K, Fujimoto H, Hase K. Predictors of extrahepatic recurrence after resection of colorectal liver metastases. Br J Surg 2004; 91: 327-333

9. Inomata M, Ochiai A, Sugihara K, Moriya Y, Yamaguchi N, Adachi Y, et al. Macroscopic Features at the Deepest Site of Tumor Penetration Predicting Liver Metastases of Colorectal Cancer. Jpn J Clin OncoI. 1998;28(2):23-128 
10. Wanebo HJ, Chu QD, Vezeridis MP, Soderberg C. Patient selection for hepatic resection of colorectal metastases. Arch Surg. 1996;131:322-9.

11. Di Martino E, Wild CP, Rotimi O, Darnton JS, Olliver RJ, Hardie LJ. IGFBP-3 and IGFBP-10 (CYR61) up-regulation during the development of Barrett's oesophagus and associated oesophageal adenocarcinoma: potential biomarkers of disease risk. Biomarkers. 2006;11:547-61.

12. Yamazoe $\mathrm{Y}$, Maetani S, Onodera H, Nishikawa T, Tobe T. Histopathological prediction of liver metastasis after curative resection of colorectal cancer. Surg Oncol. 1992;1:237-44.

13. Bird NC, Mangnall D, Majeed AW. Biology of colorectal liver metastases: a review. J Surg Oncol. 2006;94:68-80.

14. Sun L, Pan J, Peng L, Fang L, Zhao X, Sun L, et al. Combination of haptoglobin and osteopontin could predict colorectal cancer hepatic metastasis. Ann Surg Oncol. 2012;19(7):2411-9.
15. Lichao S, Liang P, Chunguang G, Fang L, Zhihua Y, Yuliang R. Overexpression of PTGIS could predict liver metastasis and is correlated with poor prognosis in colon cancer patients. Pathol Oncol Res. 2012;18(3):563-9.

16. Chen Z, Li M, Yuan Y, Wang Q, Yan L, Gu J. Cancer/testis antigens and clinical risk factors for liver metastasis of a predictive panel. colorectal cancer: Rectum. 2010;53(1):31-8.

17. Fang YJ, Lu ZH, Wang GQ, Pan ZZ, Zhou $\mathrm{ZW}$, Yun JP, et al. Elevated expressions of MMP7, TROP2, and survivin are associated with survival, disease recurrence, and liver metastasis of colon cancer. Int J Colorectal Dis. 2009;24(8):875-84. 